Mater. Sci. Bull., Vol. 1, No. 1, May 1979, pp. 35-41, Printed in India:

\title{
Glass fibre research at Indian Institute of Technology, Kanpur
}

\author{
D CHAKRAVORTY \\ Materials Science Programme and Department of Metallurgical Engineering, \\ Indian Institute of Technology, Kanpur 208016
}

MS received 25 October 1978

\begin{abstract}
Research and development on glass fibres was started at the Indian Institute of Technology (IIT), Kanpur, about three years ago. The two main directions in which efforts have been concentrated are (i) development of indigenous technology for producing glass fibres, (ii) development of new glass compositions for drawing fibres baving novel physical properties. In this note, we briefly describe the activities of this group and some of the salient results obtained so far.
\end{abstract}

\section{Ceramic bushings for drawing glass fibres}

The conventional Owens-Corning-fibre glass technology for manufacturing glass fibres uses bushings made of platinum-rhodium alloys (Lowenstein 1973). In the technique developed at IIT, Kanpur, ceramic bushings made of either pure alumina or stabilised zirconia are used for producing continuous glass fibres (Chakravorty and Bhatnagar 1976). The cost of ceramic bushings is much less than that of platinum-rhodium ones. This makes the ceramic bushing technique very attractive for setting up glass fibre units in the small scale sector.

Bushings up to 52 nozzles have been made from pure alumina by a slip cast technique (Kingery 1958). The starting material is $98.5 \%$ pure alumina supplied by Hindusthan Aluminium Corporation, ball-milled to a specific range of particle size. Stabilised zirconia obtained from Corhart Refractories have been used to cast bushings with a maximum of 26 nozzles. Zirconia from Indian Rare Earths, Hyderabad, can also be used for this purpose. Typical dimensions of the bushings are $8 \mathrm{~cm}$ in diameter and $4.5 \mathrm{~cm}$ height for cylindrical geometry and $11 \mathrm{~cm} \times$ $6 \mathrm{~cm} \times 5 \mathrm{~cm}$ for a rectangular one. Figure 1 is a photograph of bushings with different sizes and geometry made from pure alumina.

Figure 2 gives the schematic diagram of the glass fibre drawing assembly developed at IIT, Kanpur. The fiberiser in the figure consists of a set of ceramic bushings of the type described earlier. Figure 3 shows the fibre drawing plant at IIT, Kanpur. A-, C- and E-glass fibres have been drawn using this set-up. A- and C-glass were obtained from indigenous sources while E-glass developed 
at the Central Glass and Ceramic Research Institute was used for drawing fibres. The bushing tip temperatures at which fibres are drawn range from $1000^{\circ} \mathrm{C}$ to $1200^{\circ} \mathrm{C}$ with the winding drum rotating at a speed of about $1000 \mathrm{rev} / \mathrm{min}$. By varying the drum speed, fibres of diameter ranging from $4 \mu \mathrm{m}$ to $30 \mu \mathrm{m}$ have been made. The mechanical properties, e.g., ultimate tensile strength and Young's modulus of the fibres drawn through ceramic bushings compare favourably with those of commercially available fibres. For E-glass stabilised zirconia bushings are preferable because the alumina ones are corroded by this composition at a fast rate. The alumina bushings are however suitable for A- and C-glass formulations.

\section{Electrically conducting fibres}

Glasses containing metaliic particles of dimensions of the order of $100 \AA$ show electrical conductivity due to electron tunnelling between the metallic islands (Chakravorty et al 1977). Using a suitable glass composition, it has been possible to draw fibres having such a microstructure. Figure 4 is a micrograph consisting of silver particles of diameter ranging from $50 \AA$ to $1000 \AA$ dispersed in a glassy matrix. Such fibres having diameters in the range $7 \mu \mathrm{m}$ to $13 \mu \mathrm{m}$ show conductivity values of the order of $10^{8} \mathrm{ohm}-\mathrm{cm}$ (Keshavaram 1978). The dispersion of metallic particles of silver in the matrix also increases the Young's modulus of the composite as compared to that of the base glass.

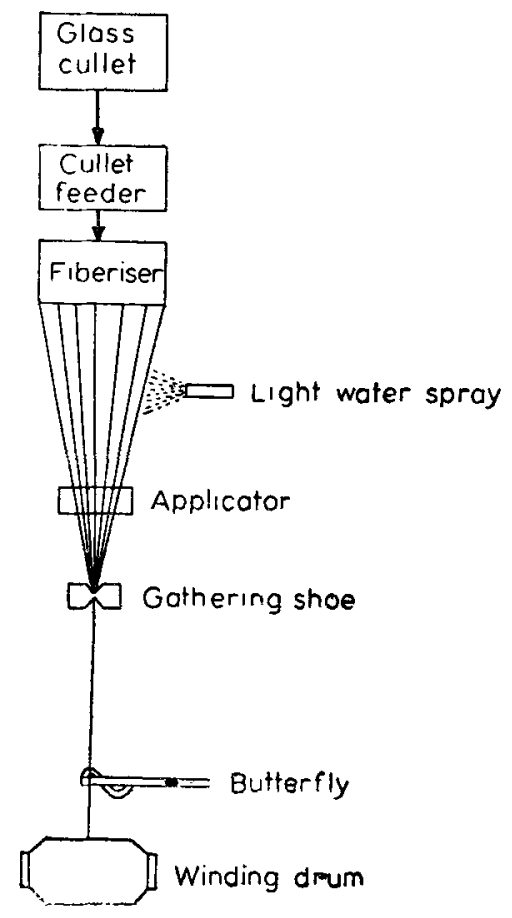

Figure 2. General lay-out of continuous fibre drawing assembly. 



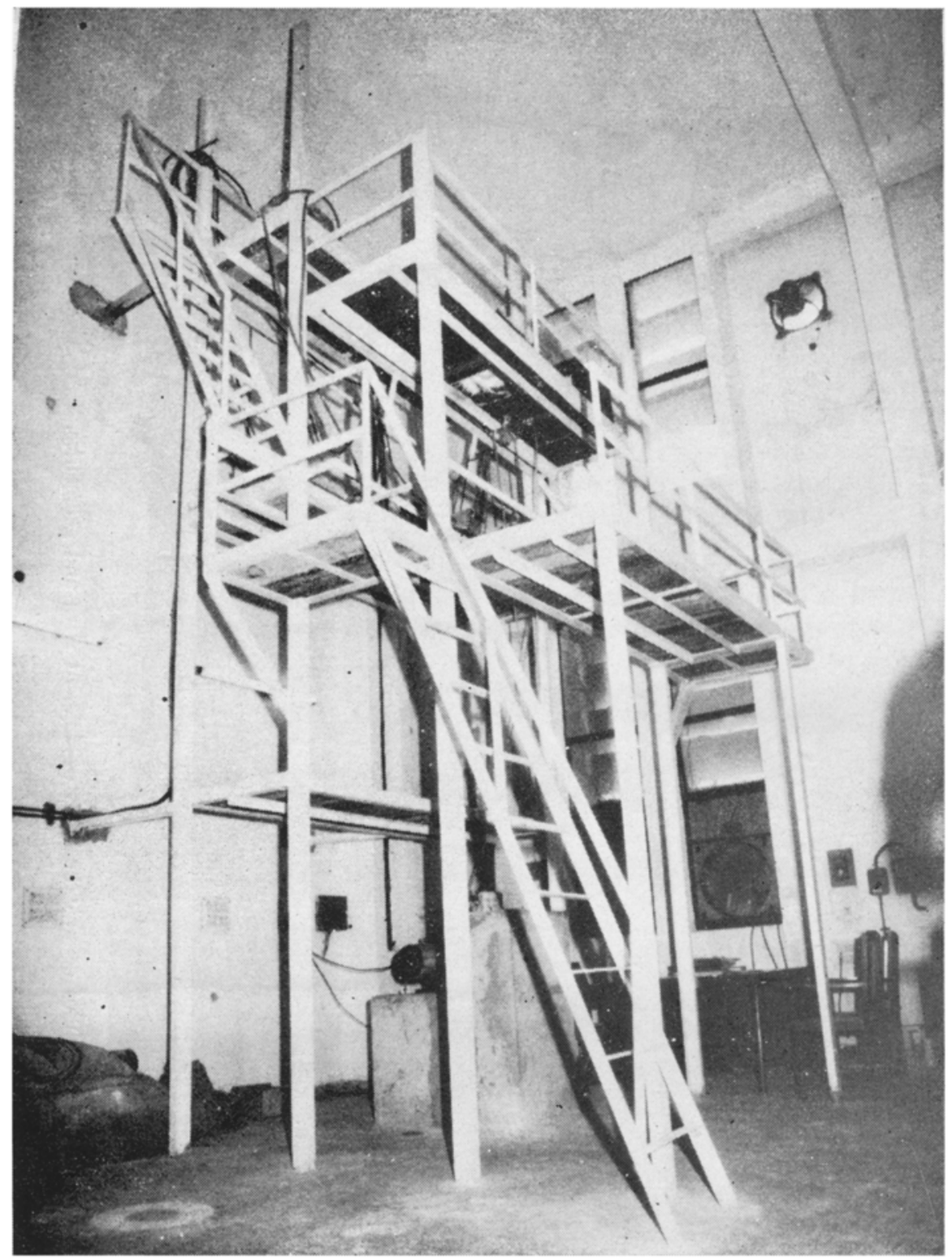

Figure 3. Photograph of glass fibre drawing plant at IIT, Kanpur. 


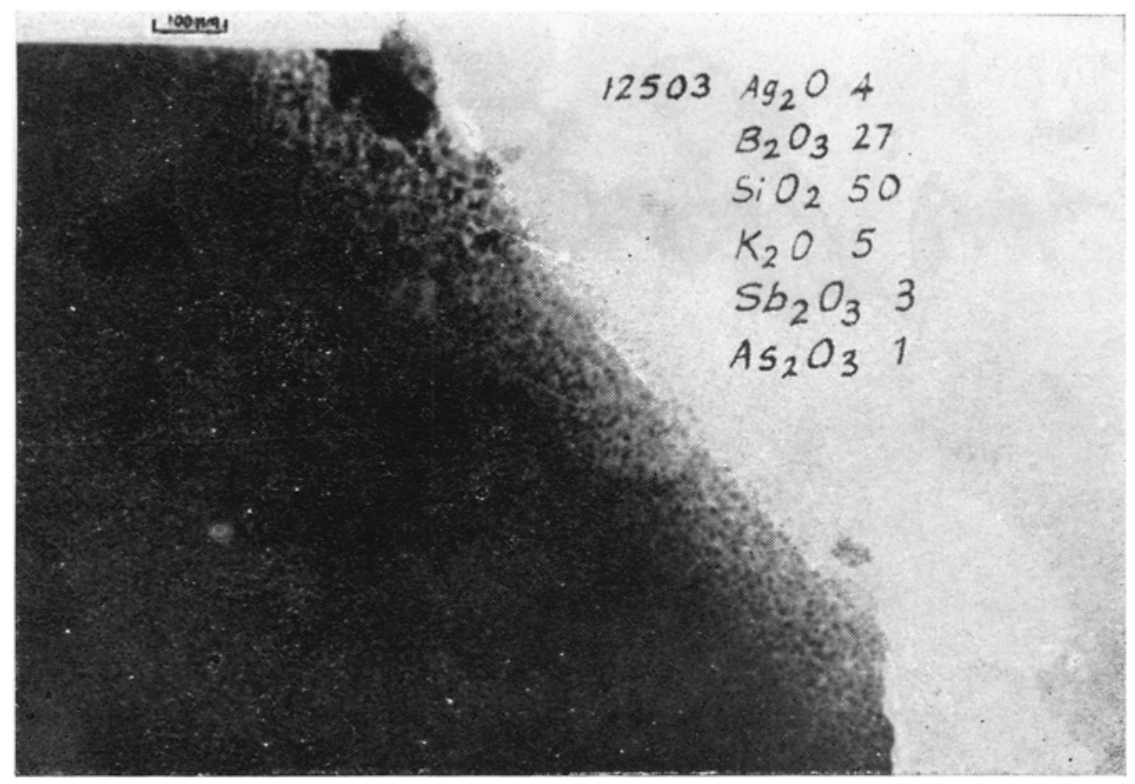

Figure 4. Electron micrograph of glass fibre contamng metallic granules. 


\section{Glass-ceramic fibres}

Glass fibres of suitable composition have been partially crystallised by subjecting them to suitable heat-treatment under a tensile stress (Shrivastava 1978). It is expected that fibres of improved mechanical strength and Young's modulus can be made by the technique. This work is now in progress.

\section{Acknowledgements}

The ceramic bushing development was supported by the Department of Science and Technology, Government of India, and the United Nations Development Programme.

\section{References}

Chakravorty D, Bandyopadhyay A K and Nagesh V K 1977 J. Phys. D10 2077

Chakravorty D and Bhatnagar R 1976 Proc. Int. Symp. Fibres and Composites NPL, New Delhi, Vol. 1, p. 7.1

Keshavaram B N 1978 Properties of glass fibres containing metallic particles, M.Tech. thesis, Indian Institute of Technology, Kanpur

Kingery W D 1958 Ceramic fabrication processes (Massachusetts : MIT Press)

Lowenstein K L 1973 The manufacturing technology of continuous glass fibres (New York : Elsevier Sci. Pub. Co.)

Shrivastava A 1978 Fibre drawing from crystallisable glasses, M.Tech. thesis, Indian Institute of Technology, Kanpur 